Document downloaded from:

http://hdl.handle.net/10251/81484

This paper must be cited as:

Andres, B.; Poler, R. (2016). A decision support system for the collaborative selection of strategies in enterprise networks. Decision Support Systems. 91:113-123. doi:10.1016/j.dss.2016.08.005.

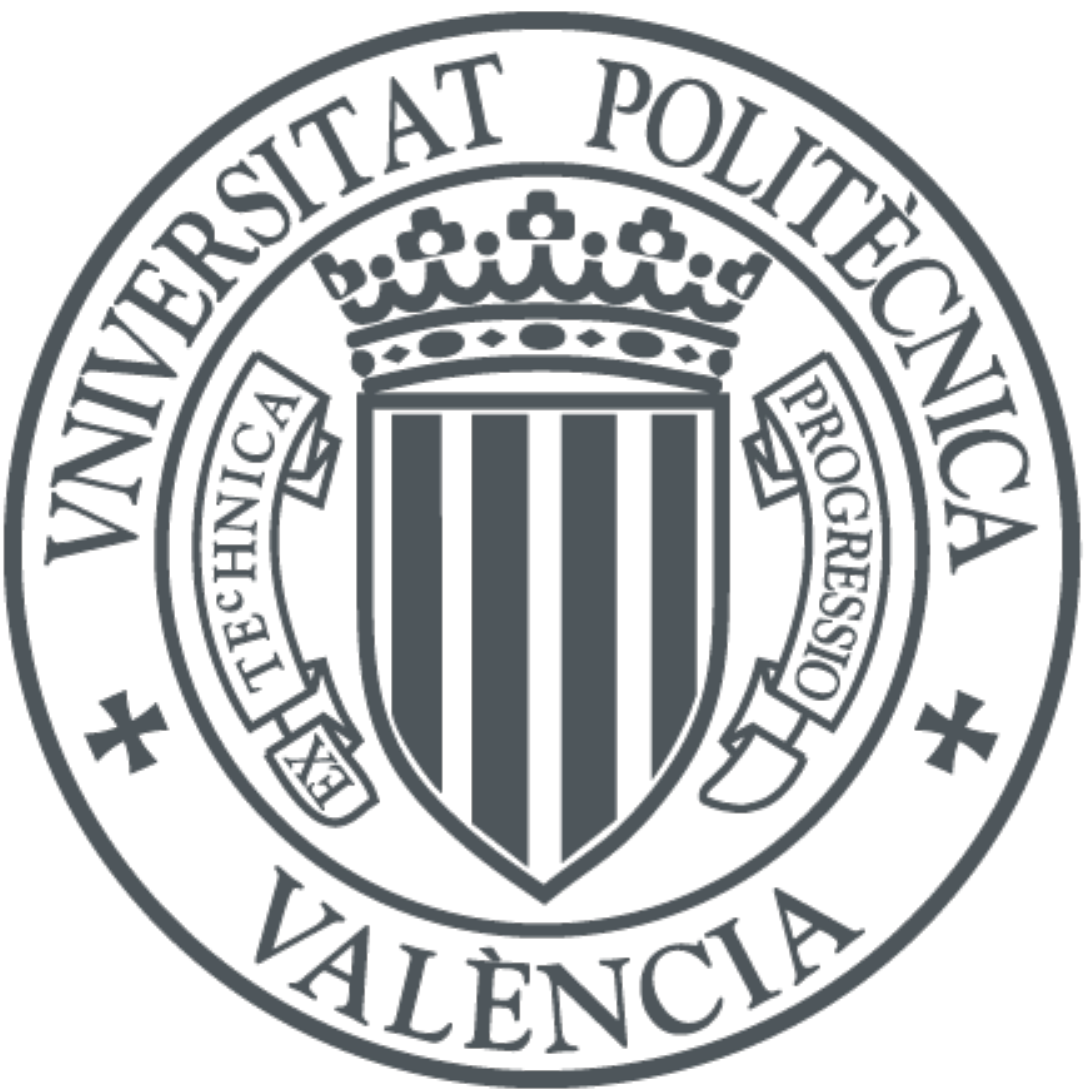

The final publication is available at

http://dx.doi.org/10.1016/j.dss.2016.08.005

Copyright Elsevier

Additional Information 


\section{Title page}

Title

A decision support system for the collaborative selection of strategies in enterprise networks

\section{Author names and affiliations}

Beatriz Andres $^{\mathrm{a}}$ and Raul Poler ${ }^{\mathrm{b}}$

${ }^{a}$ Research Centre on Production Management and Engineering (CIGIP). Escuela Politécnica Superior de Alcoy, Universitat Politècnica de València (UPV). Centre d'Innovació i Investigació. Calle Alarcón, 03801 Alcoy, Spain, bandres@cigip.upv.es

${ }^{b}$ Research Centre on Production Management and Engineering (CIGIP). Escuela Politécnica Superior de Alcoy, Universitat Politècnica de València (UPV). Centre d'Innovació i Investigació. Calle Alarcón, 03801 Alcoy, Spain, rpoler@cigip.upv.es

\section{Corresponding author}

Beatriz Andres

bandres@cigip.upv.es

+34626067352 .

Research Centre on Production Management and Engineering (CIGIP). Escuela Politécnica Superior de Alcoy, Universitat Politècnica de València (UPV). Centre d'Innovació i Investigació. Calle Alarcón, 03801 Alcoy, Spain 


\title{
A decision support system for the collaborative selection of strategies in enterprise networks
}

\begin{abstract}
Collaborative networks $(\mathrm{CN})$ consist of autonomous and heterogeneous partners, and each defines its own objectives and formulates its own strategies, which are selected and activated to achieve these objectives. The heterogeneity that characterises network partners could lead to contradictions appearing among the strategies formulated in each $\mathrm{CN}$ enterprise. Consequently, the strategies formulated in one enterprise could negatively influence the achievement of the objectives defined in other enterprises of the same network. These contradictions lead to strategies misalignments, which worsens the network performance. In order to deal with these misalignments, a DSS is proposed to support the process of selecting the strategies among all those formulated, with the aim of achieving higher alignment levels. The proposed DSS considers the impacts that each strategy formulated in each enterprise has on the performance of the objectives defined by each network partner. This allows enterprises to select a set of aligned strategies. The selection of proper strategies to be activated in each enterprise strongly influences the CN's performance level, and higher levels of network adaptability, agility and competitiveness are achieved. The proposed DSS is validated under real conditions in a food industry network. The DSS is evaluated by emulating real collaborative conditions and is compared with the equivalent non-collaborative decision making perspective used for selecting strategies. The results demonstrate that the collaborative approach outperforms the performance level of the non-collaborative one and is more effective for handling the robustness and the long-term operation of the $\mathrm{CN}$.
\end{abstract}

\section{Keywords}

Collaborative Decision Making, Decision Support System, Strategies Alignment, Key Performance Indicators, System Dynamics 


\section{Introduction}

Enterprises are continuously dealing with new decisions, and, when carrying out the decision-making process, they have to reach a decision after considering a set of potential options. The decision-making process increases in complexity when more than one actor is involved in the decision; this occurs in collaborative networks $(\mathrm{CN})$. Camarinha-Matos and Afsarmanesh [1] define $\mathrm{CN}$ as a network that consists of a variety of autonomous, geographically distributed and heterogeneous entities that collaborate to better achieve common or compatible goals, and to jointly generate value. In $\mathrm{CN}$, each enterprise defines its own objectives and formulates its own strategies; therefore, distinct interests are involved, which may lead to conflictive situations that derive from disagreements in the selection of strategies.

The processes carried out by the enterprises that belong to a $\mathrm{CN}$ are characterised by being collaborative; and have been largely studied with the aim of dealing with the associated complexity in the $\mathrm{CN}$ context. Works that are worth mentioning and propose decision-making systems to address the associated complexity, which occurs in the CN context, include [2] [3] [4]. The work carried out by [5] consolidates the wide variety of knowledge available in the collaborative domain, and proposes a comprehensive analysis of the most important collaborative processes addressed in the literature. Among all the collaborative processes identified by [5], the current paper particularly focuses on the collaborative process of selecting aligned strategies; having a strong influence on CN's success, by reducing conflicts emerging between the strategies selected and enabling higher levels of adaptability, agility and competitiveness [6].

The autonomy and heterogeneity that characterise the enterprises of a $\mathrm{CN}$ mean that each one defines its own objectives. The objectives' heterogeneity is extended to the high diversity of strategies, which are formulated as a set of actions to be performed in order to fulfil the defined objectives. The diversity of strategies may result in conflicts and contradictions among the formulated strategies. These contradictions appear when a strategy activated in one enterprise negatively influences the objectives defined by other network partners. Lack of coherence 
among the formulated strategies can lead to their misalignment. Strategies misalignments, apart from negatively influencing the objectives to be attained by each enterprise, influence the wellbeing of collaborative partners; and ultimately, strategies misalignments lead to the breakdown of the collaborative partnership if the conflicts that arise continue over time and are not dealt with [7]. Considering the importance of aligning strategies, there is a lack of an integrated DSS to assist enterprises on the strategies alignment process from a collaborative perspective. Accordingly, the following research question is raised: What would be an integrated decision making system to adequately support enterprises on the modelling, assessment and resolution of the strategies alignment selection process from a collaborative perspective?

In line with this, the present paper proposes a DSS for the Selection of Aligned Strategies (DSS-SAS) to support strategies selection, to deal with the conflicts that appear with misalignments in the $\mathrm{CN}$ context. Intuitively, as activation of strategies directly influences the achievement of objectives, it can be understood that strategies are characterised by being aligned when each activated strategy not only promotes the achievement of the objectives defined by the enterprise that formulates the strategy, but also positively influences the accomplishment of the majority of objectives defined by other network partners.

Along these lines, the paper is organised as follows: Section 2 presents the literature review in the research area of decision-making for selecting strategies; Section 3 defines proposes a collaborative decision-making model to support the selection of aligned strategies (SA-DMM). Section 4 provides the Decision Support System (DSS-SAS) to support the particular problem of selecting aligned strategies. In Section 5, the DSS-SAS is validated under real conditions for a food industry network. Finally, Section 6 presents conclusions and future research lines.

\section{Literature review}

Despite the fact that the concept of alignment has been studied in different research areas, there is a need to address this topic from the strategies selection perspective, considering the $\mathrm{CN}$ context. In order to acquire better knowledge of how the decision-making process has been 
treated in the literature, a review was carried out in the context of aligning the decisions made by the $\mathrm{CN}$ partners. It can be stated that, the strategies alignment process has its very first background in the Games Theory discipline [8] and the Nash equilibrium [9]; although he specific concept of alignment referring to enterprises' strategies has its origins in the work developed in the term fit and in the concept of strategy coalignment [10]. In order to have a better knowledge on how the strategies alignment process has been addressed a literature review is performed. The reviewed works propose models, guidelines and tools to deal with the alignment of decisions from different decision making levels and different perspectives of application (i) one in which the decisions are collaboratively made and from the beginning of the decision making the decisions are aligned, and (ii) another one in which the each partner define its own decisions and then these are pooled in order to identify those that are more aligned with the decisions of other network partners.

In the first group (i), there are worth to mention the works of: [11] that develop a centralised multi-objective linear programming model to deal with the collaborative productiondistribution planning problem in a network. The multi-criteria utility analysis method proposed by [12] to allow evaluating a set of decision-making alternatives, given a set of criteria. Fuzzy analytic hierarchy processes (FAHP) are proposed for the decision making process [13], in which weightings and rankings provide decision-makers a reference for the relative importance of the dimensions to make decisions. The alignment of decisions from a hierarchical point of view is treated in [14], in which the dominant partner of the network defines its own decisions and the other partners have to align their decisions according to the ones defined by the dominant one. [15] propose an integrated optimisation model, defining a metaheuristic genetic algorithm (GA) used to find an optimal solution for the integrated decision-making.

In the second group (ii), there are worth to mention the works of [16] and [17], in which each enterprise holds its own values and qualitative and quantitative approaches are proposed to analyse the alignment among the values. Decentralised decision-making models are used to support the modelling in different decisional centres [18]. The global decision support system model (GDSSM) [19] allows an enterprise analysing a decision under consideration and 
identifying how it favours other enterprises performance. Multi-enterprise collaborative decision support system (MECDSS) frameworks are also used [20], in which each enterprise proposes its own decisions, and dispose of all the data to identify how its decisions affect itself and its partners. The Analytic Network Process (ANP) models the prioritisations of CN partners' for determining how the decisions defined by the $\mathrm{CN}$ enterprises influence on the strategies achievement of the network [21]. Finally, [22] proposes a sequential decision problem under uncertainty, based on subjective probabilities, to evaluate the probability that a decision of one partner is optimal for itself and for another network partner.

The main weakness found in the analysed works reside in that the provided solutions only deal with the action of aligning the decisions by considering only two partners of the network, and the decisions only focus on particular types of strategies. To the best of our knowledge, there is a gap in the literature as regards the contributions that provide a holistic approach to consider all the strategies formulated by all the partners. In order to fill this gap, this research proposes an approach that supports the selection of aligned strategies from a holistic perspective in the CN context, regardless of the strategies' nature and type. In light of this, a DSS is proposed to support decision makers during the strategies selection process, which allows high alignment levels to be met between selected strategies in the $\mathrm{CN}$ environment.

\section{Decision-Making Model for the Selection of Aligned Strategies}

$\mathrm{CN}$ are characterised by enterprises' heterogeneity [1], and each one defines its own objectives, which are also heterogeneous. The strategies are the set of actions raised to achieve the defined objectives; therefore, each enterprise in $\mathrm{CN}$ formulates its own strategies in order to achieve the defined objectives. In order to achieve the alignment of strategies, the decision-making process of selecting the aligned strategies from among the enterprises of the same $\mathrm{CN}$ must be addressed. At this point, the strategies alignment concept is defined as [23]: "the set of strategies, formulated and selected by the enterprises that belong to the $C N$, whose activation positively influences, on the whole, the objectives achieved by the majority of the enterprises 
that participate in the CN, obtaining the best performance at the network level, although some of the strategies can negatively influence any of the defined objectives". A formal mathematical definition of the strategies alignment concept is presented in [23].

Regarding the decision-making in $\mathrm{CN}$, enterprises firstly define the objectives that need to be met; secondly, they formulate a set of strategies to meet these objectives (each strategy has an associated cost). Among all these strategies, enterprises have to decide which ones to select and activate in order to meet the defined objectives, and at a minimum cost. Lets suppose two enterprises, the supplier (S) and the manufacturer (M), each one defining two objectives: enterprise S defines $\mathrm{Obj}_{1 S}$ : Reduce the costs by $20 \%$ and $\mathrm{Obj}_{2 S}$ : Reduce the fluctuations in production by a 50\%, while enterprise $\mathrm{M}$ defines $O \mathrm{Obj}_{1 M}$ :Increase the net demand on an exclusive market segment by $10 \%$ and $\mathrm{Obj}_{2 \mathrm{M}}$ : Sell the 100\% of the stock next to expire. In order to achieve these objectives each enterprise formulates two strategies: enterprise $\mathrm{S}$ formulates Stra ${ }_{I S}:$ Go for a lower quality packaging and Stra ${ }_{2 S}:$ Negotiate with the partner an smoothed demand) while enterprise M formulates Stra ${ }_{1 M}$ : Promote the image of an exclusive product and Stra $_{2 M}$ : Acquire a Forecasting and Production Planning tool. In the decision making of selecting the strategies to activate, the enterprises can opt from doing it from an isolated or common perspective. In the isolated scenario, each enterprise will select the strategies that allow achieving its own objectives, without worrying about the achievement of objectives of other network enterprises. In the non-collaborative perspective, the $\mathrm{S}$ could decide to activate the $S t r_{I S}$, favouring the achievement of its $O b j_{I S}$, considered very relevant for the $\mathrm{S}$. The decision $\mathrm{S}$ of selecting the $\operatorname{Str}_{I S}$ negatively influences the achievement of $O b j_{I M}$ defined in the M, due to the increase of the net demand on an exclusive market segment will be discouraged by the reduction of quality of the products supplied by the enterprise S. In order to deal with these contradictions, a collaborative perspective for selecting the strategies is required. In response to the challenge outlined, the Strategies Alignment - Decision-Making Model (SA-DMM) is proposed to model the influences that the strategies formulated by each collaborative partner have on the objectives defined by each enterprise. The objective function of SA-DMM allows identifying the set of aligned strategies to maximise network performance through their 
selection and activation. In the proposed SA-DMM, the strategies formulated in enterprise $i$ influence the achievement of its own objectives (intra-enterprise influences are modelled); moreover, the strategies formulated in enterprise $i$ of the $\mathrm{CN}$ can influence the KPIs of another enterprise $j$, and vice versa (inter-enterprise influences are modelled). In order to represent the influences and relations between KPIs and strategies, the mathematical notation of SA-DMM is proposed. The set of parameters and decision variables used to model SA-DMM is defined in [Table 1.

[Table 1. The SA-DMM nomenclature]

SA-DMM computes the improvement or worsening of KPIs when a strategy is activated. Thus the developed SA-DMM supports enterprises in the decision of the number of units of strategy $\left(u_{-} s t r_{i s}\right)$ to be activated and the time in which the strategies have to be activated ( ti_str $_{i s}$ ) in order to maximise network performance. The objective function of SA-DMM is mathematically represented by Equation (1),given by $k p i_{n e t}^{\prime}$ the homogenised version of $k p i_{n e t}$ :

max. $\Delta k p i_{\text {net }}^{\prime}$

Two decision variables, $u_{-} s t r_{i s}$ and ti_stris, $_{\text {, }}$ are defined to maximise $k p i_{\text {net. }}^{\prime}$ Decision variable $u_{-} s t r_{i s}$ decomposes the strategy $\left(s t r_{i s}\right)$ into units of strategy. This allows the "intensity" with which each strategy $s t r_{i s}$ is carried out. One unit of strategy has an associated cost $\left(c_{-} s t r_{i s}\right)$. The total amount of monetary units spent when strategy $u_{-} s t r_{i s}$ is activated is computed by considering a linear relationship (Equation 2):

$s t r_{i s \_} m u=u_{-} s t r_{i s} \cdot c_{-} s t r_{i s}$

The budget, $b_{i}$, that each company has defines the monetary capacity constraint (Equation 3 ).

$b_{i} \geq \sum_{s} s t r_{i s-} m u \quad \forall s$

Each enterprise $i$ defines the objectives to be met, $o_{i x}$, which are measured through KPIs ( $\left.k p i_{i x k}\right)$. SA-DMM is designed and based on homogenised versions of the parameters related to KPIs. Because of this, the objective function aims to maximise $\Delta k p i_{n e t}$ in its homogenised 
version, $\Delta k p i_{n e t}^{\prime}$. Starting with $\Delta k p i_{i x k}$, its homogenised version is represented by $\Delta k p i_{i x k}^{\prime}$ and is defined as the dimensionless parameter of $\Delta k p i_{i x k}$. The estimation of $\Delta k p i_{i x k}^{\max }$ by enterprise $i$, allows us to homogenise the defined $k p i_{i x k}$ and to compare all the parameters $\Delta k p i_{i x k}$ to each other in the same enterprise and between other network enterprises. Equation 4 is applied:

$$
\Delta k p i_{i x k}^{\prime}=\frac{\Delta k p i_{i x k}}{\Delta k p i_{i x k}^{\text {max }}}
$$

As previously stated, the activation of a strategy has an influence which can be positive, negative or null for the objectives to be met. In order to identify the influence that one unit of strategy $\left(u_{-} s t r_{i s}=1\right)$ has on $k p i_{i x k}{ }_{i x k}$ parameter val_str ${ }_{i \_} k p i_{i x k}$ is used. Depending on whether $v a l_{-} s r_{i \_} k p i_{i x k}^{\prime}$ is positive or negative, $k p i_{i x k}^{\prime}$ increases or decreases when strategy $s^{\prime} r_{i s}$ is activated. By considering the values of $u_{-} s t r_{i s}$ and $v a l_{-} s t r_{i \_} k p i^{\prime}{ }_{i x k}$, parameter $i n f_{-} s t r_{i \_} k p i_{i x k}{ }_{i x}$ is computed as (Equation 5):

$$
i n f_{-} s t r_{i s_{-}} k p i_{i x k}^{\prime}=u_{-} s t r_{i s} \cdot v a l_{-} s t r_{i s_{-}} k p i_{i x k}^{\prime}
$$

The influence that one strategy $s t r_{i s}$ has on one particular $k p i_{i x k}{ }_{i x k}$ is modelled through function $f_{-} i n f_{-} s t r_{i \Sigma_{-}} k p i_{i x k}^{\prime}$. This function $f_{-} i n f_{-} s t r_{i S_{-}} k p i_{i x k}^{\prime}$ is a piecewise function that depends on time $\left[\mathrm{f}_{1}(\mathrm{t})\right]$; that is, duration parameters $\left(d 1_{-} s t r_{i s}\right.$ and $\left.d 2_{-} s t r_{i s}\right)$ and decision variable $t i_{-} s t r_{i s}$ (see [Figure 1). Decision variable ti_stris defines the starting point of $s_{\text {st }}$ and allows us to model in such a way to avoid all the strategies being activated at the same time; i.e. at the initial time $\left(t_{0}\right)$. Conversely, strategies are activated at different times $\left(t i_{-} s t r_{i s}\right)$ in the identified horizon (H). After identifying $t t_{-} s t r_{i s}$ it must be considered that $s t r_{i s}$ does not immediately influence the $k p i_{i x k}^{\prime}$ level, but is delayed, as given by $d_{1 \_} s t r_{i s .}$. Besides, $f_{-} i n f_{-} s t r_{i s_{-}} k p i_{i x k}{ }_{i x k}$ is modelled according to a ramp shape (slope_str ${ }_{i \Sigma} k p i^{\prime}{ }_{i x k}$ ) (Equation 6). The representation of the ramp allows us to model so that after the delay $\left(d_{1 \_} s t r_{i s}\right)$, str ${ }_{i s}$ progressively influences $k p i_{i x k}^{\prime}$, and this ramp depends on $d_{2} s t r_{i s}$. After passing $d_{2_{-}} s t r_{i s}$, the maximum level of influence inf_str ${ }_{i S_{-}} k p i_{i x k}^{\prime}$ is achieved ([Figure 1):

$$
\text { slope_str }{ }_{i s_{-}} k p i_{i x k}^{\prime}=\frac{i n f_{-} s t r_{i s \_} k p i_{i x k}^{\prime}}{d_{2-}^{\prime} s t r_{i s}}
$$


[Figure 1. Curve that models the influence of $s t r_{i s}$ on $k p i_{i x k}^{\prime}: f_{-} \inf \_s t r_{i s \_} k p i_{i x k}^{\prime}(t)$ ]

Function $f_{-} i n f_{-} s t r_{i \Sigma_{-}}$kpi $_{i x k}^{\prime}$ and the parameters of duration are given according to the horizon $(H)$, which is defined by the enterprises that belong to the network. Nevertheless, the proposed SA-DMM uses a normalised time horizon, which means that the total time to be modelled is the unit, $H=1$. For instance, if the problem to be modelled has a 5 -year horizon, $H=5$, this horizon in SA-DMM has to be normalised to the unit. Furthermore, the duration parameters ( $d_{1} s t r_{i s}$ and $\left.d_{2 \_} s t r_{i s}\right)$ and the decision variable ( $t i_{-} s t r_{i s}$ ) are also referred to the unit (Equations 7-10):

$H^{\prime}=\frac{H}{H}=1$

$d_{1 \_}^{\prime} s t r_{i s}=\frac{d_{1 \_} s t r_{i s}}{H} ; d_{2 \_}^{\prime} s t r_{i s}=\frac{d_{2 \_} s t r}{H} ; d_{4-}^{\prime} s t r_{i s}=\frac{d_{4-} s t r}{H}$

$d_{3 \_}^{\prime} s t r_{i s}=d_{4 \_}^{\prime} s t r_{i s}-2 \cdot d_{2 s t r_{i s}}^{\prime}-d_{1 \_}^{\prime} s t r_{i s}$

$t_{i-}^{\prime} s t r_{i s}=\frac{t_{i \_} s t r_{i s}}{H} ; t_{f-}^{\prime} s t r_{i s}=\frac{t_{f \_} s t r_{i s}}{H}$

The time constraint refers to the time instant in which the activated strategies end up (Equation 11):

$t_{f-}^{\prime} s t r_{i s} \geq H^{\prime}$

If we consider all the above, function $f_{-} i n f_{-} s t r_{i_{-}} k p i_{i x k}^{\prime}$ is mathematically represented as a piecewise function (see [Figure 1, Equation 12):

$f_{-}$inf_str ${ }_{i s \_} k p i_{i x k}^{\prime}(t)$

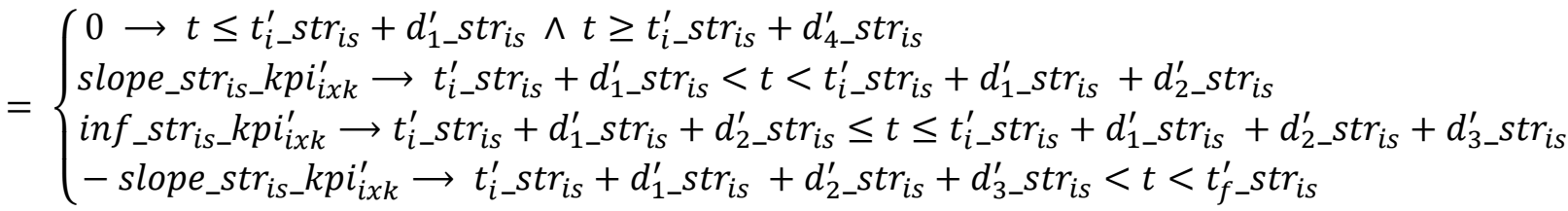

The influence on the KPIs defined in one enterprise $i$ not only depends on the strategies activated in the same enterprise, but also on the strategies activated in the other enterprises $j$ of the network. So the increase in $k p i_{i x k}^{\prime}\left(\Delta k p i_{i x k}^{\prime}\right)$ (Equation 15$)$ is caused by both intra- and inter- 
enterprise influences ( $\Delta^{i n t r a} \mathrm{kpi}_{i x k}{ }_{i x k} \Delta^{\text {inter }} \mathrm{kpi}_{{ }_{i x k}}{ }$ ), and is mathematically modelled through (Equations 13 -14):

$\Delta^{\text {intra }} k p i_{i x k}^{\prime}=\int_{t_{i-}^{\prime} s t r_{i s}+d_{1-}^{\prime} s t r_{i s}}^{H^{\prime}} f_{-} i n f_{-} s t r_{i s_{-}} k p i_{i x k}^{\prime}(t) \cdot d t$
$\Delta^{\text {inter }} k p i_{i x k}^{\prime}=\int_{t_{i_{-}}^{\prime} s t r_{j s}+d_{1-}^{\prime} \operatorname{str}_{j s}}^{H^{\prime}} f_{-} i n f_{-} s t r_{j s_{-}} k p i_{i x k}^{\prime}(t) \cdot d t$

Thus,

$\Delta k p i_{i x k}^{\prime}=\Delta^{i n t r a} k p i_{i x k}^{\prime}+\Delta^{i n t e r} k p i_{i x k}^{\prime}$

To finally characterise SA-DMM, two KPIs are defined at the enterprise and network levels:

- At the enterprise level, parameter $\Delta k p i_{i}^{\prime}$ is defined as the sum of the results perceived by each $\Delta k p i_{i x k-}^{\prime} T$ that belongs to the same enterprise $i$.

Each enterprise $i$ defines its own objectives to be met, $o_{i x}$, which are measured through KPIs $\left(k p i_{i x k}\right)$. Each $k p i_{i x k}$ has an associated weight ( $\left.w_{i x k}\right)$ (Equation 16):

$\sum_{x, k} w_{i x k}=1 \quad \forall x, k \quad$, where $w_{i x k}=[0, \ldots, 1]$

Parameter $\Delta k p i_{i}^{\prime}$ takes into account the weights defined $\left(w_{i x k}\right)$ for each $k p i_{i x k}^{\prime} \cdot \Delta k p i_{i}^{\prime}$ provides insight as to how performance behaves at the enterprise level (Equation 17).

$\Delta k p i_{i}^{\prime}=\frac{\sum_{x, k} \Delta k p i_{i x k}^{\prime} \cdot w_{i x k}}{\sum_{x, k} w_{i x k}}$

- At the network level, the $\Delta k p i_{n e t}^{\prime}$ parameter is defined as the sum of all the $\Delta k p i_{i}^{\prime}$ obtained in each network enterprise. $\Delta k p i_{n e t}^{\prime}$ provides a whole perspective as to how performance behaves at the network level (Equation 18).

$\Delta k p i_{n e t}^{\prime}=\frac{\sum_{i} \Delta k p i_{i}^{\prime}}{n}$

The main aim of the proposed mathematical optimisation model SA-DMM is to maximise the network performance level $\left(\Delta k p i_{n e t}^{\prime}\right)$. Identifying the number of units of strategies to be activated $\left(u_{-} s t r_{i s}\right)$ and the initial time when they are to be activated $\left(t i_{-} s t r_{i s}\right)$ has a positive impact on the majority of the objectives defined by the network partners. 


\section{Decision Support System for the Selection of Aligned Strategies}

In this section a DSS is presented to deal with the particular strategies alignment selection process (DSS-SAS), which is mathematically modelled in the previous section (SA-DSM). The main decision is based on selecting, from among all the formulated strategies, the strategies aligned by each network partner to obtain higher levels of network performance. The proposed DSS-SAS is software-based and combines the use of SA-DSM with a:

- a simulation software supporting system dynamics (SD) method [24], in which SA-DSM is solved. The AnyLogic simulation software is used, and SA-DSM is represented in SD

- a database that stores all the parameters required to feed SA-DSM, which are collected in a specially designed Microsoft Access Database

- the Strategies Alignment GENerator (SAGEN), an application that automatically generates SA-DSM in the AnyLogic simulation software

\subsection{DSS-SAS Simulation software}

In order to deal with the decision-making process of selecting aligned strategies, SA-DMM is constructed by representing the enterprises, their objectives and strategies, and the relations established among them. SA-DMM is proposed based on computing the increase or decrease in the performance level of the objectives according to the activated strategies. In order to solve SA-DMM, the SD method is used [26]. SD is selected because it allows representing the causal relationships between the strategies and objectives, and it models the influences that the objectives experience when a certain set of strategies is activated. Besides, SD enables to understand the structure and dynamics of complex systems, such as CN. SD is intuitive enough to represent the complex $\mathrm{CN}$ system, which consists of different autonomous enterprises in which the decisions of one node may affect the operation of other network nodes. The causal relationships between the activated strategies and the objectives (KPIs) are represented through the SD method, which allows to figure out the decision variables defined in SA-DMM, these being $u_{-} s t r_{i s}$ and $t i_{-}^{\prime} s t r_{i s}([$ Figure 2). 
[Figure 2. SA-DMM causal diagram]

AnyLogic [25] simulation software is selected to solve and represent SA-DMM according to the rigorous SD method. AnyLogic is a tool that uses a comprehensible code and Java as the implementation language. AnyLogic combines heuristics, discrete events, optimisation, agents and SD. In SD, graphical canvas is used to model the interactions that occur among the entities. SD in AnyLogic permits to define stock and flow variables, parameters and auxiliary variables, use table functions, define array variables with an arbitrary number of dimensions and define dimensions, for defining different measurements of array variables. Moreover, the models constructed in AnyLogic have the particularity of being read in XML (Extensible Markup Language). This allows SA-DMM to be built in XML and to be opened in AnyLogic. Through optimisation techniques, the AnyLogic software searches for model parameter values (decision variables) that lead to greater model performance levels, given an objective function and the set constraints and requirements. Optimisation is used in a bundle with simulation to make an efficient search. AnyLogic uses the OptQuest ${ }^{1}$ engine to carry out the optimisation of the represented simulation model. In OptQuest, if a candidate solution does not fit the requirements defined in the model, then that solution is eliminated and the candidates that are more likely to be better are explored [26]. The OptQuest provider refers to using metaheuristics, mathematical optimisation, and neural network components to guide the search to obtain the best solutions of a decision. Nevertheless for commercial reasons, the exact heuristics of optimisation is unknown. Some papers found in the literature [27] hint at the optimisation heuristics used in AnyLogic and determine that Tabu Search, Neural Networks and Scatter Search are combined into a single search heuristics to carry out the optimisation procedure.

\footnotetext{
${ }^{1}$ The OptQuest Engine obtains a sample of the objective function at the end of each simulation. The engine analyses a sample, modifies optimization parameters according to its optimization algorithm, and starts a new simulation. Optimization is an iterative process where:

- The OptQuest Engine calculates possible solutions for the parameters

- The objective function and constraints are evaluated using the suggested solutions

- The results are analysed by the OptQuest Engine, and a new set of possible solutions is calculated
} 


\subsection{The DSS-SAS Database Structure}

In order to manage and structure the parameters and the information required to feed SA-DMM, a database manager is necessary. Different types of database managers can be found: Microsoft Access Database, Microsoft SQL Server, MySQL, Oracle, PostgreSQL, XML, etc. The Microsoft Access Database manager was used to manage the DSS-SAS input data; the ease of its use was one of the main motivations for using it to structure information. The structure of the database used to support the DSS-SAS is categorised into three groups:

Data related to the SA-DMM input data. The information needed to identify each $\mathrm{CN}$ enterprise, as well as the formulated strategies and the defined KPIs. All the information on the parameters defined in SA-DMM was collected according to a relational database: (i) enterprises $i$; (ii) key performance indicators $\left(k p i_{i x k}\right)$; (iii) importance of each KPI in each enterprise ( $\left.W_{i k}\right)$; (iv) strategies $\left(u_{-} s t r_{i s}\right)$; (v) cost of the strategies $\left(c_{-} s t r_{i s}\right)$; (vi) duration of the strategies $\left(d_{t_{-}} s t r_{i s}\right)$; (vii) duration parameters $d_{\perp} s t r_{i s} d_{2} s t r_{i s}$; (viii) inter- and intra-enterprise influences val_str ${ }_{i s_{-}} k p i_{i x k}$, estimated by considering the increase of KPIs when a particular strategy is activated. Influence values remain proportional to each other; and (ix) budget that the enterprises have to activate strategies $\left(b_{i}\right)$.

Data related to the automatic construction of SA-DMM in the SD simulation software. Tables are specifically created to automatically generate SA-DMM in the SD simulation software (AnyLogic), and they contain information on the links among the parameters. These links are specifically used in the automatic construction of SA-DMM to draw the relationships between the parameters modelled in SD.

Data related to the SA-DMM output data. Two tables are created to collect the output data that correspond to the values of the decision variables: the units of strategy [u.s] $s t r_{i s}$ to be activated $\left(u_{-} s t r_{i s}\right)$ and the initial activation time of $s t r_{i s}\left(t i_{-} s t r_{i s}\right)$.

\subsection{Strategies Alignment Model Generator}

The manual modelling of the strategies alignment simulation model (in SD) can prove easy with a few enterprises, KPIs and strategies. Nevertheless, when the modeller faces a network with a 
larger number of enterprises, and each defines vast amounts of KPIs and formulates a high number strategies, the amount of parameters exponentially increases; enlarging the problem to be modelled and making its manual handling difficult. In order to avoid this tedious task, an application that automatically generates the strategies alignment simulation model was designed. The created application is called Strategies Alignment Model GENerator (SAGEM). The information stored in the created DSS-SAS database is used to this end. As the models build in AnyLogic can be read in the XML language, SAGEM builds SA-DMM in an XML file; containing structured information to represent the SA-DMM in the simulation software AnyLogic.

The programing language used to build SAGEM was Pascal. This language was selected after considering the need to use a programming language that comes as close to the natural language as possible, and whose aim is straightforward use and to expand SA-DMM in possible future developments. Lazarus [28] was used as an Integrated Development Environment (IDE) for Rapid Application Development (RAD), which uses the Free Pascal compiler.

SAGEM generates the XML code to create SA-DMM in the SD method. In addition, SAGEM has a friendly interface that allows enterprises to input the data required to feed SADMM. Therefore, it is not necessary to open the database created in Microsoft Access to introduce input data. Moreover, SAGEM creates a structured positioning of all the objects that form the strategies alignment simulation model. This structured schema allows readable simulation models to be built, which always have the same structure for SA-DMM, regardless of the number of enterprises, objectives and strategies simulated [29].

The SAGEM application works as follows: once the information has been inputted by the enterprises, Microsoft Access generates all the tables that contain all the fields needed to create the XML file that contains SA-DMM, which is to be simulated in SD in the simulation software. SAGEN is connected with Microsoft Access through an OCDBConnection. SAGEN contains a set of procedures that allows the structure required to create the XML file to be generated according to the information collected in the Microsoft Access Database. Procedures are created in accordance with the XML schema requirements for it to be read in the AnyLogic 
simulation software. SA-DMM is automatically created through SAGEN; containing the flow diagram, as well as simulation and optimisation experiments.

\subsection{Results generated by DSS-SAS: Discussion}

The proposed DSS-SAS allows us to address the selecting aligned strategies process by relating the level of performance achievement $\left(\Delta \mathrm{kpi}^{\prime}{ }_{i x k}\right)$ with the units of strategies to be activated $\left(u_{-} s t r_{i s}\right)$ and the time instant at which to activate them $\left(t i_{-}^{\prime} s t r_{i s}\right)$ by optimising global network performance $k p i^{\prime}{ }_{n e t}$. The set of strategies identified through decision variable $u_{-} s t r_{i s}$ is characterised by promoting positive influences on the majority the objectives defined by the networked enterprises, which enhances network collaborative relationships. The optimisation package of the SD simulation software (AnyLogic) provides the results of the decision variables through performing simulation runs. AnyLogic uses the OptQuest engine [26] to carry out the optimisation of the represented simulation model. In each single simulation run, the optimiser chooses different values in the parameters space. The optimiser simulates a large amount of combined parameters, and as a combinatory problem, it computes the network performance level. Different optimisation solutions are obtained and the optimiser retains the best one. The values of the parameters obtained in each iteration are collected in Data Sets. These Data Sets are stored in a table generated in a spreadsheet, which includes all the data obtained in each iteration of the optimisation experiment, including (i) the iteration number; (ii) the value of the objective in the current iteration; (iii) the feasibility of the solution, after testing that the values obtained for the decision parameters satisfy the restrictions associated with SA-DMM; (iv) the values for decision parameter $u_{-} s t r_{i s}$; and (v) the values for decision parameter $t i_{-} s t r_{i s}$. The spreadsheet collects all the iterations performed in the optimisation experiment so that all the combinations generated from the values obtained for the decision parameters $\left(u_{-} s t r_{i s}\right.$ and $\left.t_{-} s_{2} r_{i s}\right)$ are stored, which maximise the objective. Among all the solutions generated in each scenario, those that maximise the objective can be bounded. In order to select one solution $\left[u_{-} s t r_{i s}, t i_{-} s t r_{i s}\right]$ among the set of generated optimised solutions, selection rules can be applied, which can be applied according to the decision criteria considered in each enterprise; for 
example, decision criteria can be defined as regards the initial time (ti_str is $_{\text {) }}$ to activate strategies. [Table 2 lists examples of selection rules.

[Table 2. Examples of Selection Rules]

\section{DSS-SAS validation in a Food Industry Network}

The DSS-SAS is validated in a food industry network case study, by emulating real collaborative conditions and is compared with the equivalent non-collaborative decision making perspective used for selecting strategies. Therefore, the main aim is to assess whether DSS-SAS can be a useful approach for improving the decision-making process in the enterprises of a $\mathrm{CN}$. In this regard, the non-collaborative scenario has been solved to compare the performance with the collaborative scenario, in order to determine the improvements that the DSS-SAS can provide when making the decision of selecting the aligned strategies from a collaborative perspective. The non-collaborative scenario is modelled by considering, each enterprise, from an isolated perspective, in the SA-DMM model, where the parameters related with the intraenterprise influences are the only ones used. On the other hand, the collaborative scenario uses the DSS-SAS, considering the intra and inter-enterprise influences when modelling the SADMM. The data used to validate the DSS-SAS are based on a Spanish food industry network located in the province of Valencia - conveniently adapted to the particular case under study. Two companies take part in the studied network, playing the role of manufacturer and distributor. For confidentiality reasons, the names used throughout this chapter to refer to these companies are fictitious. The current decision-making process that refers to strategies activation is performed from a non-collaborative perspective. Thus, the enterprises decide in an isolated way which strategies to select and activate, and do not consider how these strategies can influence other network partners. Strategies are currently selected by considering a very simple decision-making process that only takes into account the increase of the enterprises' profits. Nevertheless, as the enterprises belong to a $\mathrm{CN}$ must be aware of considering other performance indicators, which are relevant for the other enterprises and the network operation. Therefore, all 
the KPIs defined, by each enterprise to measure the objectives achievement, have to be considered because all these KPIs will be influenced by the strategies selected not only in the enterprise itself, but also in other $\mathrm{CN}$ enterprises. The improvements obtained, through the application of DSS-SAS, are especially valuable in the food industry network because of the characteristics associated, involving quick responses and short lead times due to quick expiration time aspects.

In order to apply the DSS-SAS a complete exchange information is established between the manufacturer and distributor of the studied CN. Two agents participate in the data collection process required to feed the model: (i) on behalf the manufacturer, the Business Analyst of the Commercial Department participates; (ii) on behalf the distributor, the Head of the Area of Strategy and Business Development is involved. The network manager is in charge of collecting all the results and of using them for implementing the DSS-SAS.

The DSS-SAS solves the proposed SA-DMM in a SD software [25]. As part of the SD software, an optimisation package is employed which identifies the strategies that, if selected and activated, positively influence the majority of the objectives defined by the network partners. The optimiser maximises the network performance (kpi' $\left.{ }_{n e t}\right)$ by identifying the $u_{-} s t r_{i s}$ and $t i_{-} s t r_{i s}$ parameters of both the manufacturer and distributor. A brief description of the steps taken to implement the DSS-SAS is provided in [Table 3 [30].

[Table 3. Guideline to implement SA-DMM]

In the validation case study, the manufacturer (codified as enterprise 1: $e_{1}$ ) and the distributor (codified as enterprise 2: $e_{2}$ ) define a set of four objectives to be achieved, which are measured through the KPIs. Thus $e_{1}$ defines $k p i_{111}, k p i_{121}, k p i_{131}$, and $k p i_{141}$, while $e_{2}$ defines $k p i_{211}$, $k p i_{221}, k_{p i} i_{231}$ and $k_{p i} i_{241}$. Moreover, each KPI has its associated and corresponding weights $\left(W_{i x k}\right)$. In order to achieve the objectives, each enterprise formulates five strategies; therefore, $e_{1}$ formulates $s t r_{11}, s t r_{12}, s t r_{13}, s t r_{14}$ and $s t_{15}$, while $e_{2}$ formulates $s t_{21}, s t t_{22}, s t r_{23}, s t r_{24}$ and $s_{25}$, and they define their related data on durations and costs. The strategies formulated by the manufacturer are known and shared with the distributor, and vice versa. For this illustrative 
example, in order to maintain privacy, both strategies and KPIs are codified. The data collected by the enterprises that participate in the industrial food network, the study object, is shown in a template (see [Table 4); these data are used to feed the DSS-SAS database. [Table 4 shows the data estimated by the two enterprises of the illustrative example, defining 4 KPIs and formulating 5 strategies each one; defining the duration parameters (d1_Sis, d2_Sis, d4_Sis) and costs (c_Sis); defining the weight associated to each KPI (wik); and estimating the values of influence that the strategies have on the KPIs (val_Sis_KPIixk). In total a set of 80 parameters modelling the val_Sis_KPIixk are estimated. The set of influences is also collaboratively estimated by each network enterprise:

- Intra-enterprise influences of the manufacturer: influences that the strategies formulated by the manufacturer have on the KPIs defined by the manufacturer (val_str $\left.{ }_{1 s_{-}} k p i^{\prime}{ }_{1 \times k}\right)$. For example, if we focus on $k p i_{111}$ defined in enterprise $\left(e_{1}\right)$, strategy $s t r_{11}$ positively influences the achievement of $k p i_{111}$ if we consider that val_str ${ }_{11} k p i_{111}^{\prime}=6$, which increases the level of $k p i_{111}$.

- Intra-enterprise influences of the distributor: influences that the strategies formulated by the distributor have on the KPIs defined by the distributor (val_str $\left.{ }_{2 s_{-}} k p i^{\prime}{ }_{2 x k}\right)$. For example, if we focus on $\mathrm{kpi}_{211}$ defined in enterprise $\left(e_{2}\right)$, strategy $\operatorname{str}_{24}$ negatively influences the achievement of $k p i_{211}$ if we consider val_str ${ }_{24} k p i_{211}^{\prime}=-2$, which lowers the level of $\mathrm{kpi}_{211}$.

- Inter-enterprise influences of the manufacturer: influences that the strategies formulated by the manufacturer have on the KPIs defined by the distributor (val_str ${ }_{1 s_{-}} k p i^{\prime}{ }_{2 x k}$ ). For example, if we focus on $k p i_{211}$ defined in enterprise $\left(e_{2}\right)$, strategy $s t r_{11}$ positively influences the achievement of kpi $_{211}$ if we consider that val_str ${ }_{11} k p i_{211}^{\prime}=6$, which increases the level of $\mathrm{kpi}_{211}$.

- Inter-enterprise influences of the distributor: influences that the strategies formulated by the distributor exert have on the KPIs defined by the manufacturer (val_str ${ }_{2 s_{-}} k p i^{\prime}{ }_{1 x k}$ ). For example, if we focus on $\mathrm{kpi}_{111}$ defined in enterprise $\left(e_{1}\right)$, strategy $s t r_{21}$ negatively 
influences the achievement of $k p i_{111}$ if we consider that val_str 21 kpi' ${ }_{111}=-5$, which lowers the level of $k p i_{111}$.

The implementation of the DSS-SAS supports the decision-making of selecting aligned strategies by identifying the set of strategies $\left(u_{-} s t r_{i s}\right.$ and $\left.t i_{-} s t r_{i s}\right)$ that positively influence the achievement of the majority of objectives defined by the network enterprises. The objective is to maximise the global network performance ( $\left.k p i_{n e t}^{\prime}\right)$ while achieving the enterprises' objectives $\left(\right.$ kpi $\left.^{\prime}\right)$, improving the collaborative relationships in a given horizon.

[Table 4. Food industry case study: SA-DMM Data]

In the proposed DSS-SAS, the SA-DMM is solved through the SD method, using AnyLogic simulation software. Using the data collected form the enterprises of the food industry network, the flow diagram built in SD is generated, which represents the parameters formulated in SADMM ([Figure 3). The data collected in [Table 4 are used to feed the variables modelled in SD; moreover, for illustrating the application, only the final data are placed on the paper. By means of optimisation techniques, the AnyLogic software searches for the values of the model parameters (decision variables: $u_{-} s t_{i s}$ and $t t_{-} s t r_{i s}$ ) that help achieve the maximum performance level of the modelled network, according to the defined set constraints and requirements. A 1year (365 days) simulation horizon is considered in the experiments performed in the modelled food industry network. Optimisation is used in a bundle with simulation to perform efficient searches. In this particular case, the optimiser searches within the space of the 20 dimensional parameters, generates different simulation scenarios by combining the parameters in this space and computes the network performance level.

Two are the scenarios computed, the non-collaborative and collaborative. In the noncollaborative scenario, the enterprises only consider the intra-enterprise influences without taken into account the inter-enterprise ones. When each enterprise makes the decision of selecting strategies in isolation, then each enterprise seeks to increase its own performance and does not consider how its decisions can affect other network partners. In the collaborative scenario, the decision-making of selecting the strategies uses the proposed DSS-SAS (which 
consist of the SA-DMM, SD simulation software, DSS-SAS Database Structure and SAGEN application). The main aim of this validation is to compare both scenarios, the collaborative and the non-collaborative, in order to show enterprises another way of proceeding in the decisionmaking of selecting strategies, based on the degree of alignment; that is by considering not only the achievement of the own objectives but also the objectives of other enterprises of the $\mathrm{CN}$. The proposed DSS-SAS supports the selection of the strategies to be activated in order to achieve the best performance, and does not overload the budget. The resulting strategies are characterised by having higher alignment levels and by positively influencing the majority of the objectives defined by each network enterprise. The DSS-SAS is designed for its application in any industrial sector; moreover it could be applied in any network of organizations (although the organisations are not industrial companies) that are willing to align their strategies. The types of performance results that users could find when applying DSS-SAS, in the collaborative scenario, include: (i) all partners win (improve) in each of the performance indicators defined, so that the performance indicators at enterprises and network level are increased; (ii) some partners win in each of the performance indicators, and other partners do not win at all in each of the performance indicators, but all the partners win at the enterprise and network performance level; (iii) some partners reduce the level in some performance indicators, so that the performance indicator at the enterprise level is reduced, but the performance indicator at the network level is improved.

The results obtained, in the validation case study, reveal that the manufacturer has to activate $s \operatorname{tr}_{11}, s \operatorname{rr}_{12}, s \operatorname{sr}_{13}$ and $s \operatorname{tr}_{14}$, while the distributor has to activate $s t r_{21}, s t r_{23}, s t r_{24}$ and $s t r_{25}$. The initial activation times (in days) for each strategy are as follows: $t i_{-} s t r_{11}: 20.8$; ti_stri2: 20.8; ti_str $_{13}: 16.4$; ti_str $_{14}: 28.8$; ti_str $_{21}$ : 12.4, ti_str $_{23}: 20.8$; ti_str $_{24}: 21.5$; ti_str $_{25}$ : 13.1. From the collaborative perspective, selecting strategies decision making provides better performance results than if a decision is made in an isolated manner in each enterprise (see [Table 5). From the results (see Table 5) it can be concluded that with regards the manufacturer, the solution obtained for the collaborative scenario makes that the $\Delta \mathrm{kpi}_{1}$ is reduced by $22,2 \%\left(\Delta \mathrm{kpi}_{1}^{\mathrm{col}}=\right.$ 4,725 respect the $\left.\Delta \mathrm{kpi}_{1}^{\text {non-col }}=6,07\right)$. On the other hand, the distributor increases its 
performance level by $21,1 \%$ in the results obtained from the collaborative scenario (thus, $\Delta \mathrm{kpi}_{2}^{\text {non-col }}=8,55$ respect $\left.\Delta \mathrm{kpi}_{2}^{\mathrm{col}}=10,35\right)$. In general, the distributor increases its performance level at the expense of reducing the performance level of the manufacturer. Therefore, the manufacturer can be against the implementation of the collaborative scenario, unless the $\mathrm{CN}$ expert argues that a reduction in the level of performance of an enterprise, in the short term, will involve a more stable and sustainable long-term collaboration. Resulting in increased enterprise performance, and thus an increase in the performance at network level. Also in the $\mathrm{CN}$ validated, a simplified scenario is used, without considering the attainment of minimum levels of performance for each of the enterprise's KPIs. This consideration will be taken into account for future research. Nevertheless, it can be observed that, at last, the network performance level, $\Delta \mathrm{kpi}_{\text {net }}$, presents an improvement of 3,1\% in the collaborative scenario. The increased performance level of the distributor allows the performance improvement at the network level.

[Figure 3. Food industry case study: DSS-SAS Simulation Results]

[Table 5. Food industry case study: DSS-SAS Results]

Despite the advantages of the DSS-SAS application, the drawback related to the information collected about parameter val_stris_ $k p i_{i x k}^{\prime}$ must be taken into account. If strategy $s{ }_{i s}$ has never been activated, it is very difficult to know the value of val_stris_kpi ${ }_{i x k}{ }_{i x}$ In light of this, the enterprises that participate in the decision-making strategies selection process can opt to (i) estimate parameter val_str ${ }_{i s_{-}} k p i_{i x k}^{\prime}$ or (ii) wait until strategy $\left(s t r_{i s}\right)$ is activated and measure the real value of val_str ${ }_{i S_{-}} k p i_{i x k}^{\prime}$. If the enterprise has stored the increase in the KPIs when a specific strategy is activated, the enterprise can objectively compute val_str $i_{i_{-}} k p i_{i x k}^{\prime}$, for the strategies activated in the same enterprise, and val_str ${ }_{j \Sigma} k p i_{i x k}^{\prime}$ for the strategies activated in other network enterprises. In order to measure the precision in the estimation of the values of influence, a sensitivity analysis in the SA-DMM should be performed. The sensitivity analysis will allow determining the robustness of the SA-DMM model and the DSS-SAS. A solution will be considered to be robust when changes of the values of parameter val_str ${ }_{\text {is_ }} \mathrm{kpi}_{\mathrm{ixk}}$ involve a small 
change in the system results. Although, this sensitivity analysis is out of the scope of the proposed validation scenario, the model robustness will be demonstrated in future works.

Finally, it can be stated that the results given for the collaborative scenario provides higher levels of performance at the network level. Nevertheless, the increase of the network performance can be given due to the decrease of the some enterprises performance, as it can be seen in the food industry network studied in the validation process. The selection of strategies given by the DSS-SAS is one of the potential solutions that the enterprises can acquire to make the decision of selecting aligned strategies from a collaborative perspective. Thus far, the proposed DSS-SAS has been implemented in two real cases with collaborative networks belonging to the automotive and food industries. Following applications will be conducted in manufacturing networks of furniture and the textile industries.

\section{Conclusions}

Enterprises in $\mathrm{CN}$ are characterised by being autonomous and heterogeneous, and each one defines different objectives and formulates various strategies, which can sometimes be contradictory, negatively influencing one another. This paper addresses the decision-making process of selecting strategies from a collaborative perspective. In light of this, our paper proposes a DSS for the collaborative selection of aligned strategies among the enterprises that belong to a CN. The developed model-driven DSS architecture combines the use of: (i) a mathematical model that allows the definition of the decision context and decision criteria by representing the strategies alignment decision-making process (SA-DMM); (ii) a simulation software (AnyLogic), based on SD, used to solve SA-DMM; (iii) a database that includes all the input data needed in SA-DMM, which are required to carry out decision making; and (iv) the SAGEN application, that allows to automatically build the SA-DMM in the simulation software. The DSS-SAS allows identifying the number of units of each strategy $\left(u \_s t r_{i s}\right)$ to be activated and the time instant in which each strategy is to be activated $\left(t i{ }_{-}-s t r_{i s}\right)$, in order to maximise network performance $\left(k p i^{\prime}{ }_{n e t}\right)$. 
The usefulness of the proposed DSS-SAS lies in: (i) considering all the strategies from an holistic perspective; that is, taking into account the strategies defined in the same enterprise and in the other network partners; (ii) considering all the KPIs, and the influences that strategies have on their attainment; (iii) reducing the misalignments of the activated strategies. The strategies to be selected, resulting from the proposed DSS-SAS, favour the attainment of the majority of the objectives defined by the enterprises that participate in the network; (iv) reducing the likelihood of partnerships failure, when establishing collaborative partnerships, and the $\mathrm{CN}$ network dissolution in the long term; (v) removing selfish behaviour; and (vi) increasing network performance. The application of the proposed DSS-SAS in a real network, belonging to the food industry, illustrates its purpose. Revealing that, the use of the proposed DSS-SAS and the establishment of collaborative relationships when dealing with the decision-making process of selecting aligned strategies enhances the network performance and well-being of the relationships established in collaborative networks; allows higher levels of adaptability, agility and competitiveness levels to be achieved. These are specially valued strengths in today's turbulent contexts and dynamic markets.

Future work considerations will help with the improvement of the proposed DSS-SAS to deal with the strategies selection from a collaborative perspective. Accordingly, future research lines are led to (ii) improve the proposed SA-DMM by considering new parameters to measure the fulfilment of KPIs. To date, the developed SA-DMM assumes that selection of strategies is based on the consideration that some objectives are not fulfilled. A more realistic scenario should be modelled by considering that each enterprise decides which defined objectives must be necessarily fulfilled; (iii) run a sensitivity analysis of the solution obtained during DSS-SAS implementation. With this sensitivity analysis, collaborative enterprises will be able to identify if the optimal solution is sensitive to the changes in the values of parameter $v a l_{-} s t r_{i s_{-}} k p i_{i x k}$. The degree of robustness of the solution provided by the DSS-SAS will be identified; (iv) propose a decentralised collaborative DSS-SAS and complement it through a methodology that to support enterprises on the estimation of accurate values for parameter $v a l_{-} s t r_{i s_{-}} k p i_{i x k}$; and addresses the decision-making analysis, negotiation, conflict resolution and consensus management. The main 
aim will be to obtain an agreed solution, equally valid for all the enterprises that participate in the decision-making process. Finally, in future research applications, the proposed DSS-SAS will be implemented in different networks, consisting of different types of organisations, to validate its applicability in different sectors.

\section{References}

[1] L. M. Camarinha-Matos and H. Afsarmanesh, "Collaborative networks : a new scientific discipline” Journal of Intelligent Manufacturing, vol. 16, no. 4-5, pp. 439-452, 2005.

[2] P. S. Tan, S. S. G. Lee, and A. E. S. Goh, "Multi-criteria decision techniques for contextaware B2B collaboration in supply chains" Decision Support Systems, vol. 52, no. 4, pp. 779-789, 2012.

[3] Y. Kristianto, A. Gunasekaran, P. Helo, and M. Sandhu, "A decision support system for integrating manufacturing and product design into the reconfiguration of the supply chain networks" Decision Support Systems, , vol. 52, no. 4, pp. 790-801, 2012.

[4] J. E. Hernández, J. Mula, R. Poler, and A. Lyons, "Collaborative Planning in Multi-tier Supply Chains Supported by a Negotiation-Based Mechanism and Multi-agent System” Group Decision and Negotiation, vol. 23, no. 2, pp. 235-269, 2014.

[5] B. Andres and R. Poler, "Models, guidelines and tools for the integration of collaborative processes in non-hierarchical manufacturing networks: a review" International Journal of Computer Integrated Manufacturing, vol. 2, no. 29, pp. 166$201,2016$.

[6] R. Poler, L. M. Carneiro, T. Jasinski, M. Zolghadri, and P. Pedrazzoli, Intelligent Nonhierarchical Manufacturing Networks. Networks and Telecomunications Series. 2012. iSTE WILEY, 2012.

[7] B. Andres and R. Poler, "Improving the collaborative network performance through the activation of compatible strategies" International Journal of Engineering Management 
and Economy, vol. 5, no. 1/2, pp. 35-47, 2015.

[8] J. Von Neumann and O. Morgenstern, Theory of games and economic behavior. Princeton University Press, Princeton, 1947.

[9] J. F. Nash, "Non-cooperative games" PhD Dissertation, Princeton, 1950.

[10] N. Venkatraman and J. E. Prescott, "Environment-strategy coalignment: an empirical test of its performance" Strategic Management Journal, vol. 11, pp. 1-23, 1990.

[11] H. Selim, C. Araz, and I. Ozkarahan, "Collaborative production-distribution planning in supply chain: A fuzzy goal programming approach" Transportation Research Part E: Logistics and Transportation Review, vol. 44, no. 3, pp. 396-419, May 2008.

[12] X. F. Zha, R. D. Sriram, M. G. Fernandez, and F. Mistree, "Knowledge-intensive collaborative decision support for design processes: A hybrid decision support model and agent" Computers in Industry, vol. 59, no. 9, pp. 905-922, 2008.

[13] T. P. Lu, A. J. C. Trappey, Y. K. Chen, and Y. D. Chang, "Collaborative design and analysis of supply chain network management key processes model" Journal of Network and Computer Applications, vol. 36, no. 6, pp. 1503-1511, 2013.

[14] H. Seok, S. Y. Nof, and F. G. Filip, "Sustainability decision support system based on collaborative control theory" Annual Reviews in Control, vol. 36, no. 1, pp. 85-100, 2012.

[15] S. D. Dao, K. Abhary, and R. Marian, "Optimisation of partner selection and collaborative transportation scheduling in Virtual Enterprises using GA" Expert Systems with Applications, vol. 41, no. 15, pp. 6701-6717, 2014.

[16] V. Martinez and U. Bititci, "Aligning value propositions in supply chains" International Journal of Value Chain Management, vol. 1, pp. 6-18, 2006.

[17] P. Macedo, A. Abreu, and L. M. Camarinha-Matos, "A method to analyse the alignment of core values in collaborative networked organisations" Production Planning \& Control, vol. 21, no. 2, pp. 145-159, 2010. 
[18] M. M. E. Alemany, F. Alarcón, F. C. Lario, and J. J. Boj, “An application to support the temporal and spatial distributed decision-making process in supply chain collaborative planning” Computers in Industry, vol. 62, no. 5, pp. 519-540, 2011.

[19] H. W. Lin, S. V. Nagalingam, S. S. Kuik, and T. Murata, "Design of a Global Decision Support System for a manufacturing SME: Towards participating in Collaborative Manufacturing" International Journal of Production Economics, vol. 136, no. 1, pp. 1$12,2012$.

[20] F. Shafiei, D. Sundaram, and S. Piramuthu, "Multi-enterprise collaborative decision support system" Expert Systemps with Applications, vol. 39, no. 9, pp. 7637-7651, 2012.

[21] M. J. Verdecho, J. J. Alfaro, and R. Rodriguez, "Prioritization and management of interenterprise collaborative performance" Decision Support Systems, vol. 53, no. 1, pp. 142$153,2012$.

[22] R. Guillaume, G. Marques, C. Thierry, and D. Dubois, "Decision support with ill-known criteria in the collaborative supply chain context" Engineering Applications of Artificial Intelligence, vol. 36, pp. 1-11, 2014.

[23] B. Andres and R. Poler, "Computing the Strategies Alignment in Collaborative Networks" in Enterprise Interoperability VI. Interoperability for Agility, Resilience and Plasticity of Collaborations, K. Mertins, F. Bénaben, R. Poler, and J.-P. Bourrières, Eds. Cham: Springer International Publishing, 2014, pp. 29-40.

[24] J. W. Forrester, Industrial dynamics. Cambridge, MA: MIT press., 1961.

[25] AnyLogic, “AnyLogic.” 2015.

[26] J. P. C. Kleijnen and J. Wan, "Optimization of simulated systems: OptQuest and alternatives" Simulation Modelling Practice and Theory, vol. 15, no. 3, pp. 354-362, 2007.

[27] L. Bianchi, M. Dorigo, L. M. Gambardella, and W. J. Gutjahr, "A survey on metaheuristics for stochastic combinatorial optimization" Natural Compututing: an 
international journal, vol. 8, no. 2, pp. 239-287, 2008.

[28] Lazarus Free Pascal, “Lazarus.” 2015.

[29] B. Andres, R. Poler, J. Rosas, and L. M. Camarinha-Matos, "A Decision-Support Tool to Deal with the Strategies Alignment Process in Collaborative Networks," IFIP Advances in Information and Communication Technology, vol. 470, pp. 3-10, 2016.

[30] B. Andres and R. Poler, "Towards a Methodology to support the Strategies Alignment Process in Collaborative Networks," in Enterprise Interoperability VII. Enterprise Interoperability in the digitized and networked Factory of the Future, 2016, p. (In press). 
Table 1. Nomenclature of SA-DMM

\begin{tabular}{|c|c|}
\hline Index & \\
\hline net & set of networks, net $=(1, \ldots, N)$ \\
\hline$i$ & set of enterprises, $i=(1, \ldots, I)$ \\
\hline$x$ & set of objectives, $x=(1, \ldots, X)$ \\
\hline$k$ & set of key performance indicators, $k=(1, \ldots, K)$ \\
\hline$s$ & set of strategies where $s=(1, \ldots, S)$ \\
\hline \multicolumn{2}{|l|}{ Model Parameters } \\
\hline$n$ & number of enterprises that belong to the network \\
\hline$o_{i X}$ & objective $x$ defined in enterprise $i$ \\
\hline$b_{i}$ & $\begin{array}{l}\text { budget owned by the enterprise } i \text { to invest in the activation of strategies stris, in monetary } \\
\text { units [m.u.] }\end{array}$ \\
\hline stris & strategy $s$ defined by enterprise $i$ \\
\hline$k p i_{i x k}$ & key performance indicator (KPI) $k$ used to measure objective $o_{i x}$ \\
\hline$\Delta k p i_{i x k}$ & $\begin{array}{l}\text { increase observed in } k p i_{i x k} \text { when } s t r_{i s} \text { is activated. It can be decomposed in: } \\
\text { - } \Delta k p i_{i x k}^{\text {intra }} \text { increase of } k p i_{i x k} \text { when the } s t r_{i s} \text { of the same enterprise } i\left(e_{i}\right) \text { is } \\
\text { activated } \\
\text { - } \Delta k p i_{i x k}^{\text {inter }} \text { increase of } k p i_{j x k} \text { when the } s t r_{j s} \text { of a different enterprise } j\left(e_{j}\right) \text { is } \\
\text { activated }\end{array}$ \\
\hline$\Delta k p i_{i x k}^{\max }$ & maximum increase of $k p i_{i x k}$ estimated by enterprise $i$ (used to homogenise all the KPIs) \\
\hline$W_{i x k}$ & weight of $k p i_{i x k}$, determines the relevance of $k p i_{i x k}$ for enterprise $i$ \\
\hline$\Delta k p i_{i}$ & increase undergone by the KPI defined at the enterprise $i$ level \\
\hline$\Delta k p i_{\text {net }}$ & increase undergone by KPI defined at the network net level \\
\hline$f_{-} i n f_{-} s t r_{i s_{-}} k p i_{i x k}(t)$ & function that models the behaviour of $k p i_{i x k}$ when $s t r_{i s}$ is activated \\
\hline c_stris & cost of activating one unit of strategy stris [m.u.] \\
\hline str is $_{-} m u$ & monetary units invested in the activation of $\operatorname{str}_{i s}[\mathrm{~m} . \mathrm{u}]$. \\
\hline val_stris_kpi $i_{i x k}$ & $\begin{array}{l}\text { numerical value estimated by enterprise } e_{i} \text {, that registers the increase or decrease in } k p i_{i x k} \\
\text { when one unit of } s t r_{i s} \text { is activated }\left(u_{-} s t r_{i s}\right)\end{array}$ \\
\hline inf_stris_ $k p i_{i x k}$ & $\begin{array}{l}\left.\text { maximum level of influence on } k p i_{i x k} \text { when a certain number of units of strategy ( } u_{-} s t r_{i s}\right) \\
\text { is activated }\end{array}$ \\
\hline slope_stris_kpiixk & slope of the ramp in represented in $f_{-} i n f_{-} s t r_{i s-} k p i_{i x k}(t)$ \\
\hline$H$ & $\begin{array}{l}\text { horizon, time units [t.u.], period of time during which the set of strategies are to be } \\
\text { activated. Normalised to the unit, } H=1 \text {. }\end{array}$ \\
\hline$d_{1}$ str $_{i s}$ & $\begin{array}{l}\text { delay, time period between the initial activation time of } s t r_{i s}\left(t{ }_{-} s t r_{i s}\right) \text { and the time when } \\
k p i_{i x k} \text { is started to be influenced by the activated } s t r_{i s}[\mathrm{t} . \mathrm{u} .]\end{array}$ \\
\hline$d_{2}$ str $_{i s}$ & $\begin{array}{l}\text { time period between } s t r_{i s} \text { starts to influence } k p i_{i x k} \text { until the maximum level of influence is } \\
\text { achieved (inf_stris_kpixk), [t.u.] }\end{array}$ \\
\hline$d_{3}{ }_{-}$stris & $\begin{array}{l}\left.\text { time period during which } s t r_{i s} \text { exerts the strongest influence (inf_str }{ }_{i S_{-}} k p i_{i x k}\right) \text { on } k p i_{i x k} \\
\text { [t.u.] }\end{array}$ \\
\hline$d_{4} \_s t r_{i s}$ & total duration of $s t$ Is $_{\text {is }}$ [t.u.] \\
\hline tf_stris & time unit when $s t_{i s}$ is finished [t.u.] \\
\hline \multicolumn{2}{|l|}{ Decision Variables } \\
\hline $\begin{array}{l}\text { u_stris } \\
\text { ti_stris }\end{array}$ & $\begin{array}{l}\text { units of strategy [u.s] stris to be activated } \\
\text { initial time of activation of } s t r_{i s} \text { [t.u.] }\end{array}$ \\
\hline
\end{tabular}


Table 2. Examples of Selection Rules

\begin{tabular}{l|c}
\hline \hline \multicolumn{1}{c|}{ Selection rule } & Mathematical notation \\
\hline $\begin{array}{l}\text { The activation time of the strategies whose } \\
\text { decision variable } u_{-} s t r_{i s}>0 \text { must be as soon/ } \\
\text { later as possible; e.g. during the first/later half } \\
\text { period of the simulation horizon }\end{array}$ & $\sum_{i} t_{i-}^{\prime} s t r_{i s}<\frac{H^{\prime}}{2} \quad \forall s$ \\
\hline & $\sum_{i} t_{i-}^{\prime} s t r_{i s}>\frac{H^{\prime}}{2} \quad \forall s$ \\
$\begin{array}{l}\text { The activation time between the strategies } \\
\text { whose decision variable } u_{-} s t r_{i s}>0 \text { must be as } \\
\text { long/short as possible }\end{array}$ & $\max \sum_{s, c}\left(t_{i-}^{\prime} s t r_{i s}-t_{i-}^{\prime} s t r_{i c}\right)$ \\
& $\min \sum_{s, c}\left(t_{i-}^{\prime} s t r_{i s}-t_{i-}^{\prime} s t r_{i c}\right)$ \\
$\begin{array}{l}\text { The activation time of a specific strategy } \\
\text { whose } u_{-} s t r_{i s}>0 \text { must be before/after/between } \\
\text { a defined time: }\end{array}$ & $t_{i-}^{\prime} s t r_{i s} \leq t$ \\
& $t 1<t_{i-}^{\prime} s t r_{i s}>t$ \\
\hline \hline
\end{tabular}




\section{Steps Description}

Step 1 Select the enterprises that participate in the decision-making process to select aligned strategies. Identification of DSS users. In this particular case, the manufacturer and distributor are identified for the participation in the collaborative decision making to select aligned strategies.

Step 2 Collect the data required to feed the model in the DSS database:

- Identify in each enterprise the set of objectives $\left(o_{i x}\right)$ defined and the KPIs used to measure the level of achievement of these objectives ( $\left.k p i_{i x k}^{\prime}\right)$. Information on the importance that each KPI has for each participating enterprise $\left(w_{i k}\right)$ is also collected.

- Identify in each enterprise the set of strategies formulated to reach the objectives $\left(u_{-} s t r_{i s}\right)$. The formulated strategies form part of the set of potential options to decide which strategies to select. These strategies include those that will be potentially activated. The information that characterises the strategies is also collected, including (i) the cost of the formulated strategies $\left(c_{-} s t r_{i s}\right)$, (ii) the duration of the formulated strategies $\left(d_{4_{-}} s t r_{i s}\right)$ and (iii) the values of parameters $d_{1 \_} \operatorname{str}_{\text {is }} d_{2 \_}$str $_{\text {is }}$

- The budget owned to activate the strategies $\left(b_{i}\right)$

Step 3 The enterprises jointly estimate the values of influence (val_str ${ }_{i s_{-}} k p i_{i x k}, v a I_{-} s t r_{i s_{-}} k p i_{j x k}$ and val_str $\left.j_{j \_} k p i_{j x k} v a l_{-} s t r_{j \_} k p i_{i x k}\right)$ that the strategies $\left(u_{-} s t r_{i s}\right)$ have in the KPIs ( $\left.k p i_{i x k}{ }_{i x k}\right)$.

Step 4 Automatically build the SA-DMM in SAGEM application. The SA-DMM will be built in the simulation software (AnyLogic) byg the SD method, and by considering the data collected in the DSS database

Step 5 Simulate the SA-DMM by using the optimisation and simulation experiments offered by the simulation software, and obtain the decision variables $\left(u_{-} s t r_{i s}\right.$ and $\left.t i_{-} s t r_{i s}\right)$ that optimise network performance ( $\left.k p i^{\prime}{ }_{n e t}\right)$ 


\section{Table 4. Pilot 1: SA-DMM Data}

\begin{tabular}{|c|c|c|c|c|c|c|c|c|c|c|c|c|c|c|}
\hline \multicolumn{15}{|c|}{ Manufacturer } \\
\hline \multicolumn{15}{|c|}{$\mathrm{b} 1=14$} \\
\hline & & & & & & & KPI111 & & KPI121 & & KPI131 & & KPI141 & \\
\hline & & & & & & & W11 & 0,25 & W12 & 0,25 & W13 & 0,25 & W14 & 0,25 \\
\hline S11 & c_S11 & 1 d1_S11 & $0 \quad \mathrm{~d} 2 \_\mathrm{S} 11$ & 0,0001 & d4_S11 & 0,6 & val_S11_KPI111 & 6 & val_S11_KPI121 & 0 & val_S11_KPI131 & -2 & val_S11_KPI141 & -1 \\
\hline S12 & c_S12 & 5 d1_S12 & $0 \quad \mathrm{~d} 2 \_\mathrm{S} 12$ & 0,0001 & d4_-S12 & 0,6 & val_S12_KPI111 & -5 & val_S12_KPI121 & 0 & val_S12_KPI131 & 0 & $\mathrm{val}^{-} \mathrm{S} 12 \mathrm{KPI} 141$ & 0 \\
\hline S13 & c_S13 & 4 d1_S13 & $0 \quad \mathrm{~d} 2 \_\mathrm{S} 13$ & 0,0001 & d4__S13 & 0,6 & val_S13_KPI111 & 6 & val_S13_KPI121 & 0 & val_S13_KPI131 & 0 & val_S13_KPI141 & 0 \\
\hline S14 & c_S14 & 3 d1_S14 & 0 d2_S14 & 0,0001 & d4_S14 & 0,6 & val_S14_KPI111 & 4 & val_S14_KPI121 & 0 & val_S14_KPI131 & 0 & val_S14_KPI141 & 0 \\
\hline \multirow[t]{6}{*}{ S15 } & c_S15 & 2 d1_S15 & 0 d2_S15 & 0,0001 & d4_S15 & 0,6 & val_S15_KPI111 & 3 & val_S15_KPI121 & 0 & val_S15_KPI131 & 0 & val_S15_KPI141 & 0 \\
\hline & & & & & & & $\mathrm{val}^{-} \mathrm{S} 21^{-} \mathrm{KPI} 111$ & -5 & $\mathrm{val}^{-} \mathrm{S} 21^{-} \mathrm{KPI} 121$ & 0 & $\mathrm{val}^{-} \mathrm{S} 21^{-} \mathrm{KPI} 131$ & 2 & val S21 KPI141 & 0 \\
\hline & & & & & & & val_S22_KPI111 & -3 & val_S22_KPI121 & 0 & val_S22_KPI131 & -3 & val_S22_KPI141 & 6 \\
\hline & & & & & & & val_S23_KPI111 & 2 & val_S23_KPI121 & 0 & val_S23_KPI131 & -1 & val_S23_KPI141 & 2 \\
\hline & & & & & & & val_S24_KPI111 & -3 & val_S24_KPI121 & -4 & val_S24_KPI131 & 8 & val_S24_KPI141 & 10 \\
\hline & & & & & & & val_S25_KPI111 & 1 & val_S25_KPI121 & 0 & val_S25_KPI131 & 0 & val_S25_KPI141 & 1 \\
\hline \multicolumn{15}{|c|}{ Distributor } \\
\hline \multicolumn{15}{|c|}{$\mathrm{b} 2=5$} \\
\hline & & & & & & & KPI211 & KPI2 & & KPI231 & & KPI241 & & \\
\hline & & & & & & & W21 & 0,25 & W22 & 0,25 & W23 & 0,25 & W24 & 0,25 \\
\hline S21 & c_S21 & 1 d1_S21 & $0 \quad \mathrm{~d} 2 \_\mathrm{S} 21$ & 0,0001 & d4_S21 & 0,6 & val_S11_KPI211 & 6 & val_S11_KPI221 & 0 & val_S11_KPI231 & -2 & val_S11_KPI241 & -1 \\
\hline S22 & c_S22 & 1 d1_S22 & $0 \quad \mathrm{~d} 2 \_\mathrm{S} 22$ & 0,0001 & d4__S22 & 0,6 & val_S12_KPI211 & 10 & val_S12_KPI221 & 0 & val_S12_KPI231 & 0 & val_S12_KPI241 & 0 \\
\hline S23 & c_S23 & 1 d1_S23 & 0 d2_S 23 & 0,0001 & d4__S23 & 0,6 & val_S13_KPI211 & 5 & val_S13_KPI221 & 0 & val S13 KPI231 & 0 & $\mathrm{val}^{-} \mathrm{S} 13^{-} \mathrm{KPI} 241$ & 0 \\
\hline S24 & c_S24 & 1 d1_S24 & 0 d2_S24 & 0,0001 & d4_S24 & 0,6 & val_S14_KPI211 & 2 & val_S14_KPI221 & 0 & val_S14_KPI231 & 0 & val_S14_KPI241 & 0 \\
\hline \multirow[t]{6}{*}{ S25 } & c_S 25 & 2 d1_S25 & $0 \mathrm{~d} 2-\mathrm{S} 25$ & 0,0001 & d4_-S25 & 0,6 & val_S15_KPI211 & 0 & val_S15_KPI221 & 0 & val_S15_KPI231 & 0 & val_S15_KPI241 & 0 \\
\hline & & & & & & & val_S21_KPI211 & 0 & val_S21_KPI221 & 8 & val_S21_KPI231 & 0 & val_S21_KPI241 & 0 \\
\hline & & & & & & & val_S22_KPI211 & 0 & val_S22_KPI221 & 0 & val_S22_KPI231 & -3 & val_S22_KPI241 & 6 \\
\hline & & & & & & & val_S23_KPI211 & 4 & val_S23_KPI221 & 0 & val_S23_KPI231 & -1 & val_S23_KPI241 & 2 \\
\hline & & & & & & & val_S24_KPI211 & -2 & val_S24_KPI221 & -4 & val_S24_KPI231 & 8 & val_S24_KPI241 & 10 \\
\hline & & & & & & & val_S25_KPI211 & 0 & val_S25_KPI221 & 0 & val_S25_KPI231 & 0 & val_S25_KPI241 & 1 \\
\hline
\end{tabular}


Table 5. Food Industry Pilot: DSS Results

\begin{tabular}{|c|c|c|c|c|}
\hline & & $\begin{array}{c}\text { Non-Collaborative } \\
\text { Scenario } \\
\end{array}$ & $\begin{array}{l}\text { Collaborative } \\
\text { Scenario } \\
\end{array}$ & $\begin{array}{l}\text { Performance } \\
\text { Improvement }\end{array}$ \\
\hline \multirow{4}{*}{$\begin{array}{l}\text { Manufacturer } \\
\text { (Enterprise 1) }\end{array}$} & $\nabla \mathrm{kpi}_{11}$ & 9 & 5.4 & $-40.0 \%$ \\
\hline & $\nabla \mathrm{kpi}_{12}$ & -3.6 & -3.6 & $0.0 \%$ \\
\hline & Dkpi13 & 3.6 & 6.3 & $75.0 \%$ \\
\hline & $\nabla \mathrm{kpi}_{14}$ & 15.3 & 10.8 & $-29.4 \%$ \\
\hline \multirow{4}{*}{$\begin{array}{l}\text { Distributor } \\
\text { (Enterprise 2) }\end{array}$} & $\nabla \mathrm{kpi}_{21}$ & 13.5 & 22.5 & $66.7 \%$ \\
\hline & $\nabla \mathrm{kpi} 22$ & 3.6 & 3.6 & $0.0 \%$ \\
\hline & $\nabla \mathrm{kpi}_{23}$ & 1.8 & 4.5 & $150.0 \%$ \\
\hline & $\nabla \mathrm{kpi}_{24}$ & 15.3 & 10.8 & $-29.4 \%$ \\
\hline Manufacturer & $\Delta k p i_{1}$ & 6.075 & 4.725 & $-22.2 \%$ \\
\hline Distributor & $\Delta k p i_{2}$ & 8.55 & 10.35 & $21.1 \%$ \\
\hline Pilot 1 & $\Delta k p i_{n e t}$ & 7.313 & 7.538 & $3.1 \%$ \\
\hline
\end{tabular}




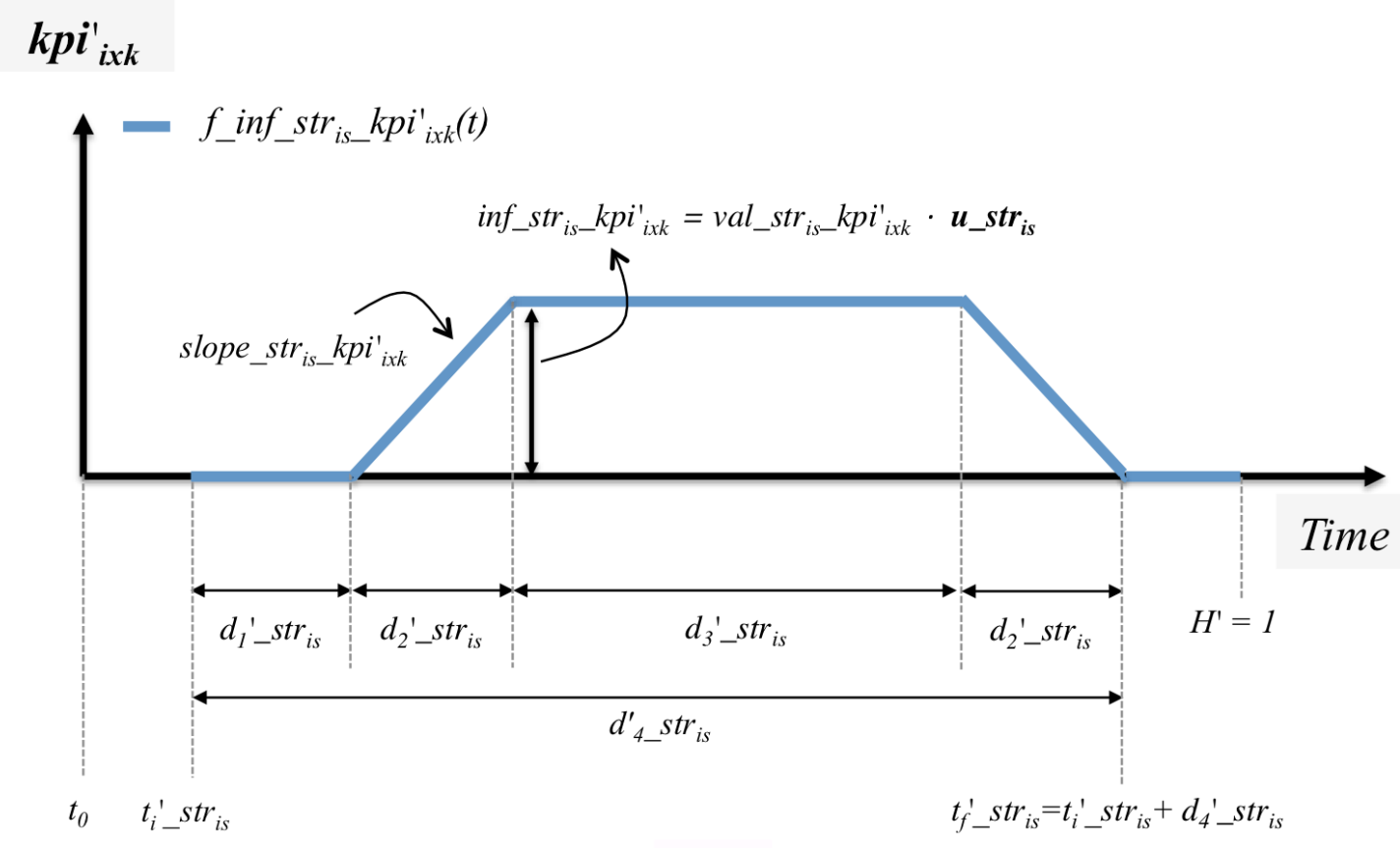

Figure 1. Curve that models the influence of $s t r_{i s}$ on $k p i_{i x k}^{\prime}: f \_$inf _str $r_{i s-} k p i_{i x k}^{\prime}(t)$ 


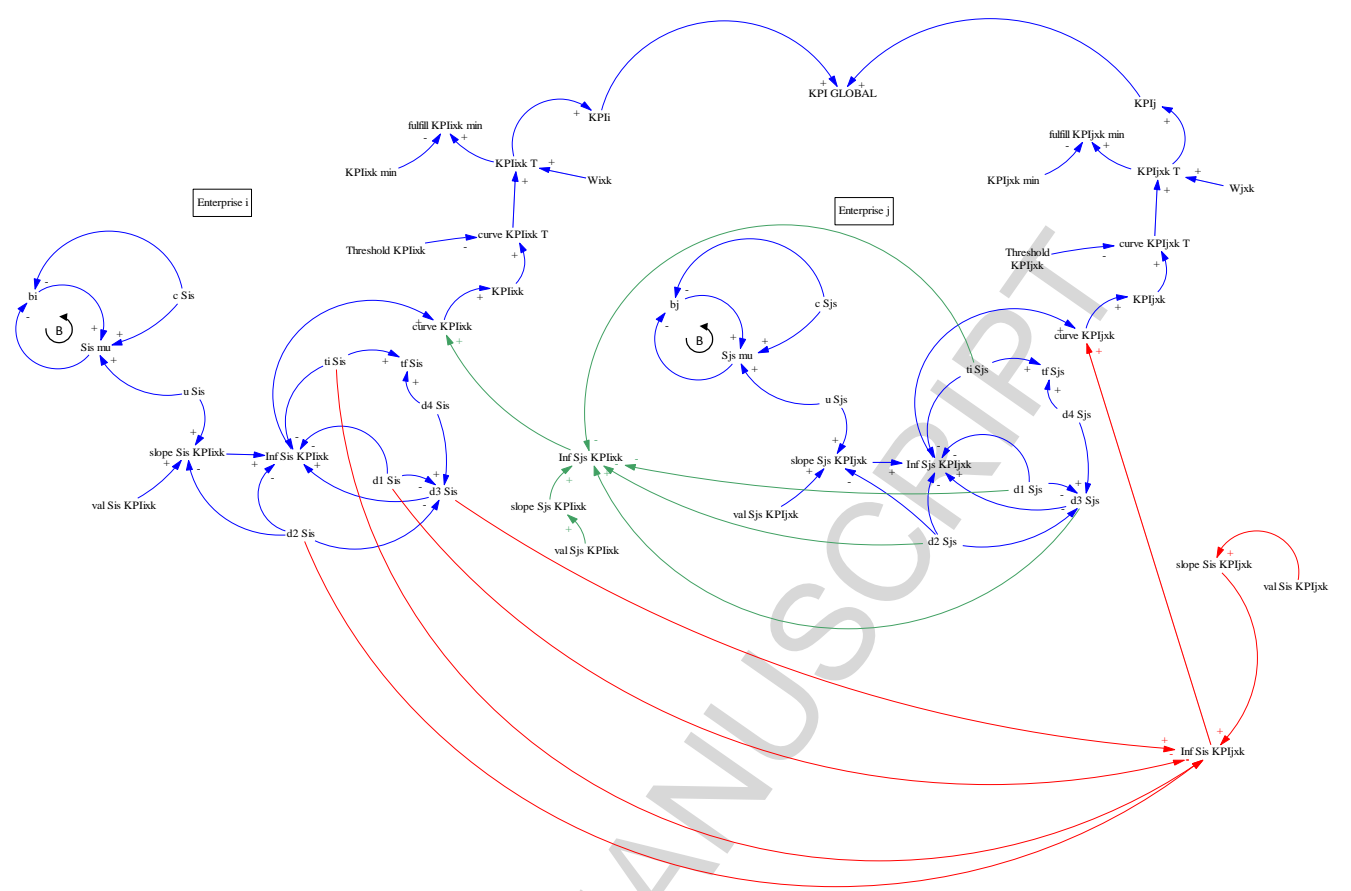

Figure 2. SA-DMM causal diagram 


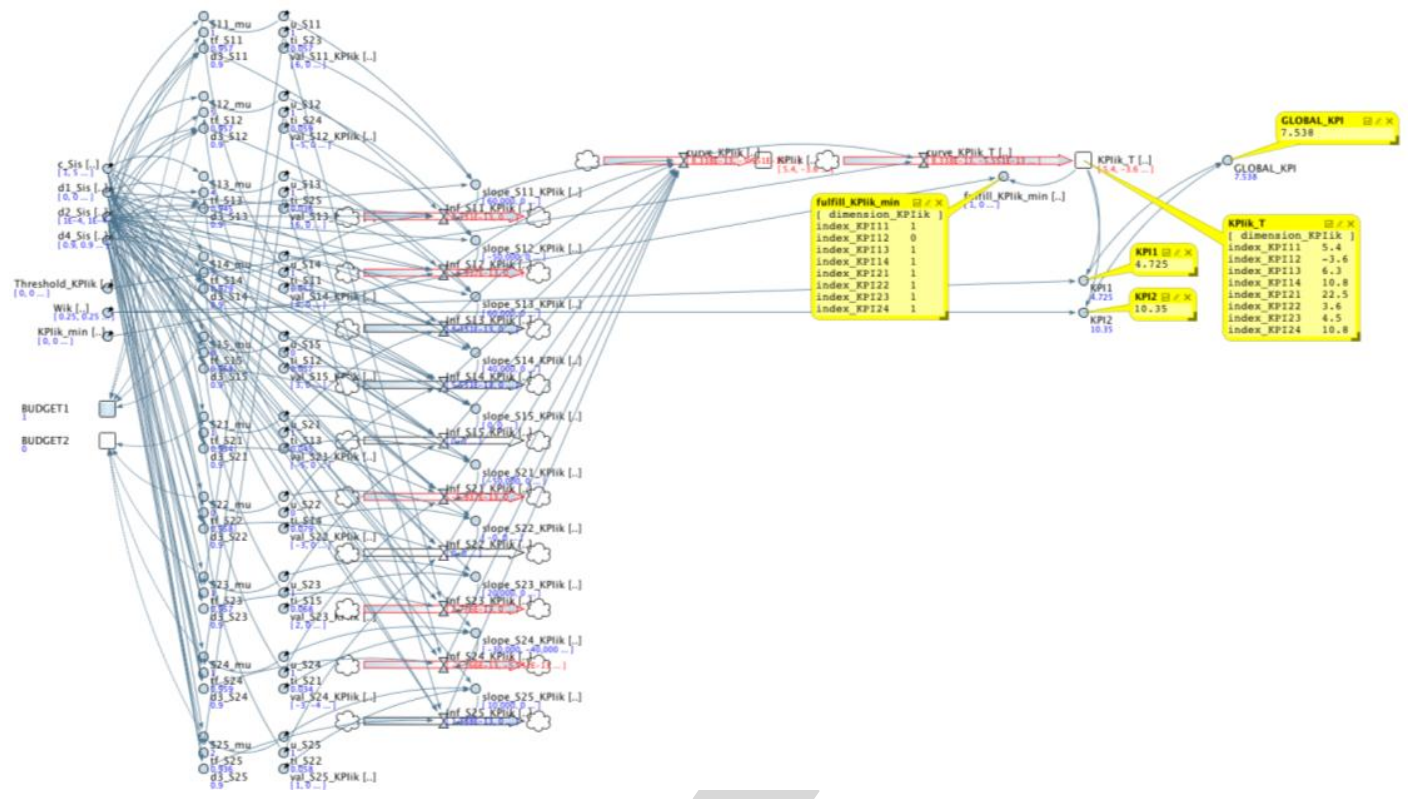

Figure 3 Food Industry Pilot: DSS Simulation Results 


\section{Authors Biography}

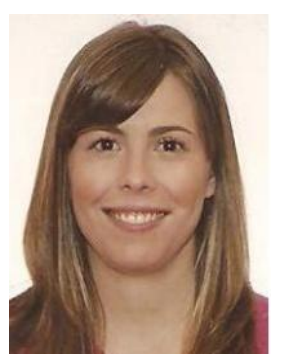

Beatriz Andrés received her PhD in Enterprise Engineering and Production in 2016 at the Universitat Politècnica de Valencia (UPV) funded by Programa VALi+d per a Investigadors en Formació from Valencian Government. She has a Master on Advanced Engineering in Production, Logistics and Supply Chain of UPV. She is member of Research Centre on Production Management and Engineering (CIGIP) from UPV. He has participated in several Spanish Government and European R\&D Projects. Her current research focuses on the areas of Collaborative Networks, Strategies Alignment, Decision Support Systems, Non-Hierarchical Manufacturing Network. She is member of the Socolnet Society, a community of researchers and professionals in Collaborative Networks. She has published several research papers international conferences and indexed journals.

Raul Poler is Professor in Operations Management and Operations Research

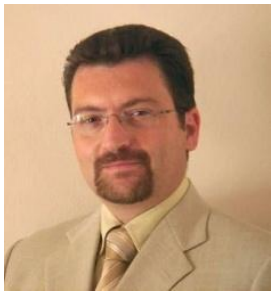
at the Universitat Politècnica de Valencia (UPV). He received his $\mathrm{PhD}$ in Industrial Engineering in 1998. He is Director of the Research Centre on Production Management and Engineering (CIGIP). He has led several Spanish Government and European R\&D Projects. He has published a hundred of research papers in a number of leading journals and international conferences. He is the Representative of INTERVAL (the Spanish Pole of the INTEROP-VLab). He is member of the Association for the Organisation Engineering (ADINGOR) and the IFIP WG 5.8 Enterprise Interoperability among other. His key research topics include Enterprise Modelling, Decision Support Systems, Collaborative Networks, Knowledge Management, Production Planning and Control and Supply Chain Management. 


\section{Highlights}

- A Decision Support System (DSS) is presented in the collaborative networks (CN) context

- The DSS deals with strategies misalignments among the enterprises of CN

- The DSS supports SMEs during the selecting strategies process based on achieving higher alignment levels

- The proposed DSS is holistic enough, considering the impacts that each formulated strategy, in each enterprise, have on meeting the objectives defined by each network partner

- Selected strategies are characterised by being aligned, and positively influence the CN's performance level, thus achieving higher levels of network adaptability, agility and competitiveness 